\title{
Mathematical Support of Decision Support System When Managing A Company
}

\author{
A.A. Mitsel ${ }^{1,2}$, S.V. Kozlov ${ }^{1}$, M.Yu. Kataev ${ }^{1,2}$, A.V. Maslov ${ }^{1}$ \\ Information Systems Department \\ ${ }^{1}$ Yurga Institute of Technology of National Research Tomsk Polytechnical University, Russia \\ 2 Tomsk State University of Control Systems and Radioelectronics, Russia \\ maa@asu.tusur.ru,kmy@asu.tusur.ru,maslovav@tpu.ru
}

\begin{abstract}
Under current conditions it is impossible to manage a company to a good quality without specialized instruments. Currently decision support systems (DSS) are widely used to manage the bankruptcy risks of a company. Developing a DSS requires proper mathematical models. It allows return on capital forecasting and financial solvency revealing and, mainly, regulating the risk of bankruptcy event.
\end{abstract}

The aim of the given paper is to throw light on the problem of decision support system development when estimating financial stability of companies. In the paper we consider the mathematical support of DSS - models of financial stability estimation and dynamic model of managing the resultant index of financial stability. In the paper we review the methods of bankruptcy risk estimation described in academic literature and describe some models developed by the authors.

In the paper the authors provide a brief review of DSS designed for managing the bankruptcy risk of companies, analyze the financial stability of $\mathbf{3 0}$ oil and gas companies organized as open joint stock companies. It was shown that there are no universal models for estimating company bankruptcy risk. The limits to applicability of the models depend upon the economic conditions under which the models were developed, notably, it was shown that foreign models are insufficient for Russian conditions. The authors provide their models of financial stability estimation of oil and gas and machine-building companies which allow taking into consideration quantitative and qualitative indices which can be both standardized and non-standardized. The models allow taking into account industry-specific peculiarities of companies and can be applied to estimate the bankruptcy risk. (Abstract)

Keywords - systems of decision support, financial stability, bankruptcy, bankruptcy risk models, factor analysis, discriminate models, fuzzy set models

\section{INTRODUCTION}

Under current conditions it is impossible to manage a large company to a good quality without specialized instruments. Currently the decision support systems (DSS) are actively applied when managing various economic entities and organization structures [1-8] including company bankruptcy risk management [911]. DSS development requires proper mathematical models.

Decision support system is a computer automated system which assists managers in making decisions under the complicated conditions of informational flow diversity for the most complete and objective analysis of company activities. As today, from the point of view of most large company managers the most relevant task is sensible forecasting of possible problems and timely detecting current problems as well as searching for optimal solutions for the given problems, then, a mature and faultless DSS is an original "magic wand" for many companies.

Decision support systems also find application in the sphere of bankruptcy forecasting. As DSS not only helps finding the most optimal solution of the problem but may also forecast appearing of the problem, then, in the sphere of bankruptcy forecasting, DSS is rather widely applied. DSS also allows timely revealing signs of false bankruptcies. False bankruptcies include fictitious or deliberate bankruptcies and it is an undeniable advantage as bankruptcies of this kind cause the greatest harm in the sphere of company bankruptcies.

\section{DECISION SUPPORT SYSTEMS}

DSS is the result of integration of managerial information systems and systems of database management. This system is designed for supporting decisions involving rather large amount of criteria. This means that estimation of results is completed according to several criteria at once.

DSS provides comprehensive analysis of the possible solutions for the problem and chooses one, the most optimal, of them and in the course of analysis of possible solutions ranges all of them in general in terms of preferability. According to the given aggregate of criteria DSS compares and estimates the solutions and helps the user in favor of the best one. 
A. DSS in the sphere of bankruptcy forecasting. Domestic and foreign experience

The term "bankruptcy" is rather widely used and it cannot be given one clear definition. Various financial difficulties of the companies in this or that case can be called a bankruptcy. It may be financial insolvency (income does not cover the expenses), pay inability of the company (inability to settle with creditors in time), pre-bankruptcy pay inability (exceeding the creditor indebtedness of the general value of a business) or bankruptcy (insolvency) acknowledged by arbitrary court.

DSS is applied to predict financial difficulties of that kind and find the best way of solving these difficulties.

Yusupova N.I. and Volik Ye.O. in their paper [3] "Bankruptcy monitoring with application of data intellectual analysis methods" provide an example of a framework of the supervision system on bankruptcy legitimateness with application of information technologies. The given framework is presented in Fig.

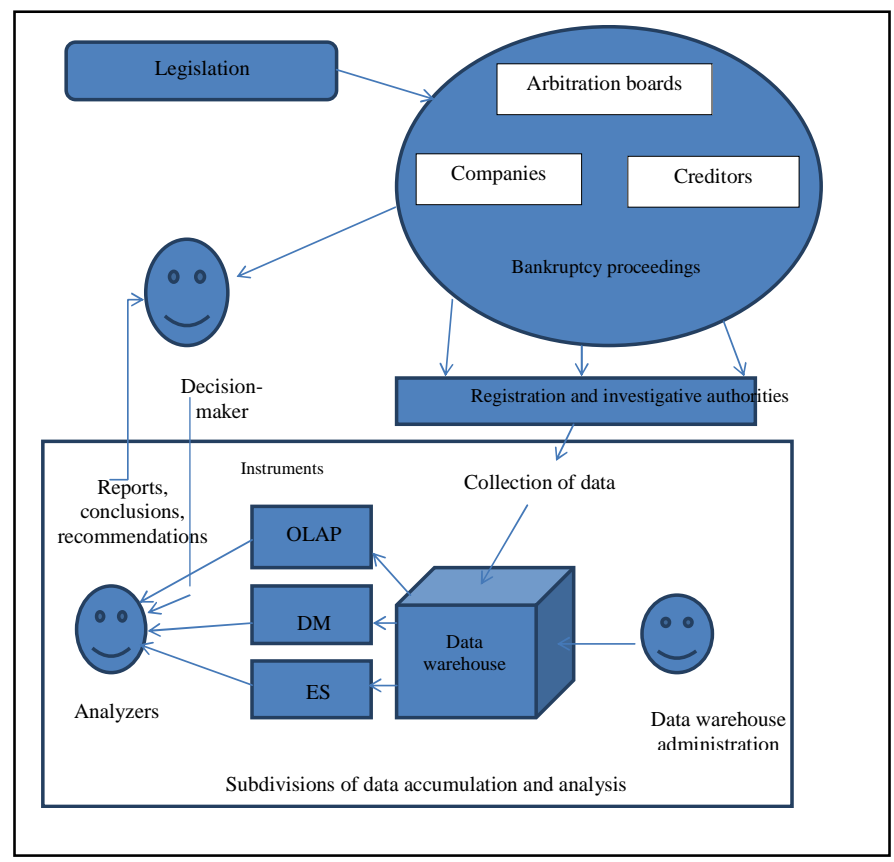

1.

Fig. 1. Framework of the supervision system on bankruptcy legitimateness [3]

Figure 1 shows that the objects of monitoring are bankruptcy proceedings, the subjects are proper regulatory authorities capable of decision-making. The decision-makers are authorities and subdivisions accumulating and analyzing data (registration and investigative authorities, subdivisions of data accumulation and analysis). These data, after cleaning and filtering must be kept in data warehouse (DW). This data warehouse is then applied for investigation of these or those aspects of bankruptcies. Thus, modern information technologies including DSS provide tools for comprehensive analysis of data in DW to analyzers. These instruments include online analytical processing (OLAP), data "mining"/extraction of data from DW, expert system (ES) or knowledge-based system. The given instruments comprise various aspects of data analysis process and, thus, should be used as a single package.

As far as foreign application of DSS in the sphere of bankruptcy forecasting is concerned one of new methods is developing and application of artificial neural networks analysis (ANNA). The principle of such neural network development is based on the study of "hidden" dependences between different variables which are later included into non-linear model of bankruptcy forecasting as explanatory variables.

The method of ANNA forecasting can be considered as DSS as artificial neural network is the result of technology progress in the field of artificial intelligence development and simulation of human thinking algorithms. Artificial neural networks are capable of efficient recognition of patterns basing on accumulated experience and learning from mistakes.

The base for neural networks development are studies of structure and work of human and animal brain and neural system.

Both approaches to bankruptcy forecasting have their advantages and disadvantages. It is up to company management which of them to apply.

Decision support system in company management is one of the most important and reliable systems which can be used to prevent failures and mistakes in the process of company activity management.

To develop DSS it is necessary to have mathematical models of company bankruptcy estimation (financial stability) as well as of model of managing financial stability of a company.

In the given work the authors consider mathematical models of company financial stability estimation and dynamic management model.

\section{Models Of FinANCIAL Stability Estimation}

Long-term financial stability of a company is usually estimated by a system of indices which includes a number of basic divisions: estimation of property position; liquidity estimation; financial stability estimation; business activity estimation; profitability estimation. Each group includes from 6 to 12 different indices (in general 41) [12, 13].

Beside ratio analysis a number of classification models distinguishing bankrupt companies from stable borrowers and forecasting possible bankruptcy of borrow company [12-23]. 
There many proprietary technologies of bankruptcy probability estimation operating by a wide range of indices. Such factor models were developed with application of multivariate analysis (multiplicative) discriminatory analysis [20, p. 186].

The most well-known models of bankruptcy probability estimation include:

- $\quad$ Altman models [12, 13,14];

- Four-factor Lis model which is suitable for Russian companies with such legal organizational form as CJSC and OJSC [21];

- $\quad$ Fulmer Model - nine factors model to assess the risk of bankruptcy [23]

$\bullet$

- Model of company bankruptcy by SaifullinKadykov is a medium-term rating model of bankruptcy risk predicting developed by Russian scientists which can be applied for any industry and companies of various scale $[16,26]$;

- $\quad$ Springate model of company bankruptcy prediction $[17,18]$;

- $\quad$ Four-factor bankruptcy model by Taffler [15, $18]$.

\section{Altman model.}

This model was introduced by Altman in 1968. Was studied 66 American industrial enterprises, 33 of which were officially declared bankrupt. The group of active companies was randomly selected based on two criteria: industry and firm size. The sample includes only large (the size of assets \$ 1-25 million\$) industrial enterprises. On the basis of financial analysis on selected companies, Altman chose 22 financial statements index most sensitive to the probability of bankruptcy. These indicators were then classified in 5 categories, characterizing liquidity, profitability, leverageability of the company (the dependence on borrowed capital), solvency and business activity. From each category was selected by one indicator that is most common in financial literature and are statistically significant. On the basis of these indicators and using a number of statistical assumptions was recorded following discriminant function:

$$
\begin{aligned}
& Y=0,717 \cdot a 1+0,847 \cdot a 2+3,107 \cdot a 3+, \\
& +0,420 \cdot a 4+0,995 \cdot a 5
\end{aligned}
$$

where $\mathrm{a}_{1}$ - own working capital/total assets; $\mathrm{a}_{2}-$ undistributed profit of prior years/total assets; $a_{3}-$ earnings before interest and taxes/total assets; $\mathrm{a}_{4}-$ monetary assets/full balance cost of liabilities; $a_{5}-$ sales revenues/total assets. When: $\mathrm{Z}<0$ - the probability of bankruptcy maximum $(0.9-1), 0<\mathrm{Z}<0.18-$ the probability of bankruptcy is high $(0.6-0.8), 0.18<\mathrm{Z}<$ 0.32 - probability of bankruptcy of medium (0.35-0.5), $0.32<\mathrm{Z}<0.42$ is the probability of bankruptcy is low
(0.15-0.20), $\mathrm{Z}>0.42$ is the probability of bankruptcy is negligible (up to 0.1 ).

On the base of annual accounting reports of 30 oil and gas companies with legal organization form of open joint stock company for 2010, 2011 and 2012 values of $a_{1}, a_{2}, a_{3}, a_{4}$ and $a_{5}$ were calculated and financial stability of these companies was analyzed.

Analysis showed that five-factor Altman model scarcely reflects the real situation in Russian companies and does not predict their further development. Thus, according to the results of Z-factor 17 per cent of companies had extremely high probability of bankruptcy, 30 per cent had high probability, 0 per cent - possible and 53 - very low probability of bankruptcy (Fig. 2). In fact, 100 per cent of companies continued their activities in 2012 and, thus, we should have supposed that 100 per cent of companies must have had low probability of bankruptcy.

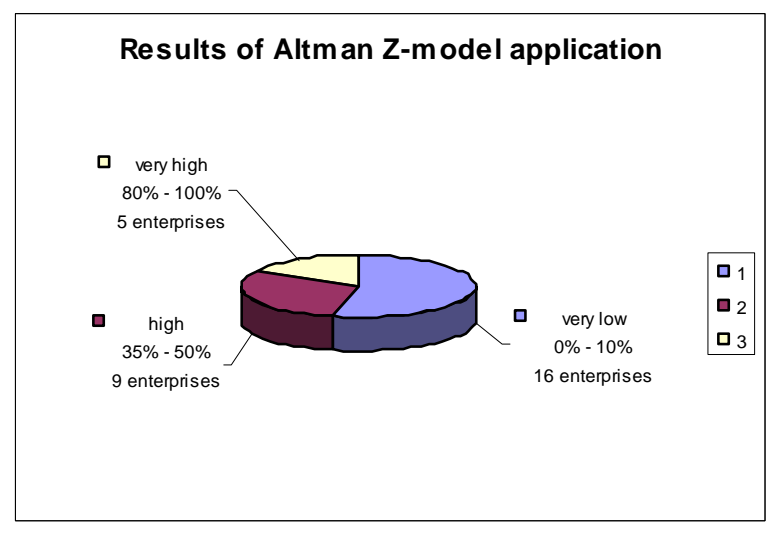

Fig. 2. Results of Altman Z-model application

Lis model of bankruptcy probability estimation [21] looks as

$$
Z=0,063 \cdot X 1+0,092 \cdot X 2+0,057 \cdot X 3+0,001 \cdot X 4,
$$

where $X_{1}$ - current asset to total asset ratio; $X_{2}$ - return on total assets according to sales profit; $\mathrm{X}_{3}$ - return on total assets according to undistributed profit; $\mathrm{X}_{4}-$ financing ratio.

In paper [24] to predict the financial position of mobile communication companies MTS, Megafon and Beeline on the base of annual accounting reports during 20032013 [25-27] the authors suggest vector autoregressive model of Lis Z-score which allows taking into consideration mutual influence of companies upon financial activities of each other. the model looks as follows

$\left(\begin{array}{l}z_{1} \\ z_{2} \\ z_{3}\end{array}\right)_{t}=\left(\begin{array}{ccc}0,96 & 0 & 0 \\ 0 & 0,961 & 0 \\ 0 & 0 & 0,95\end{array}\right) \cdot\left(\begin{array}{l}z_{1} \\ z_{2} \\ z_{3}\end{array}\right)_{t-1}+\left(\begin{array}{l}-1,38 \cdot 10^{-3} \\ -2,08 \cdot 10^{-3} \\ -9,45 \cdot 10^{-3}\end{array}\right)^{T} \cdot X_{1, t-1}+$ 
$+\left(\begin{array}{c}-4,32 \cdot 10^{-4} \\ 0 \\ 0\end{array}\right)^{T} \cdot X_{2, t-1}+\left(\begin{array}{c}0 \\ -7 \cdot 10^{-4} \\ -5,7 \cdot 10^{-3}\end{array}\right)^{T} \cdot X_{3, t-1}+$

$+\left(\begin{array}{c}-8,3 \cdot 10^{-4} \\ -1,42 \cdot 10^{-4} \\ -9 \cdot 10^{-4}\end{array}\right)^{T} \cdot X_{4, t-1}+\varepsilon_{t}$

here $\quad z_{1}-Z$-score for MTS;

$z_{2}-Z$-score for Megafon;

$z_{3}-Z$-score for Beeline.

$X_{j}$ - vector of $\mathrm{J}$-th indicator which components are related to company number, $j=1, \ldots, 4$.

The model is stable as the stationary condition is fulfilled - all characteristic values of ratio matrix under $Z_{t-1}$ are negative.

Prediction built according to obtained model shows that all companies demonstrate hopeful prospects of financial stability, are not subjected to bankruptcy risk.

Among the domestic methods of company bankruptcy risk estimation we can distinguish the fivefactor MDA-model developed by R.S. Saifullin and G.G. Kadykov. The model looks as follows [28]:

\section{$\mathrm{R}=2 \cdot \mathrm{K} 1+0,1 \cdot \mathrm{K} 2+0,08 \cdot \mathrm{K} 3+0,45 \cdot \mathrm{K} 4+\mathrm{K} 5$,}

where ratios $\mathrm{K}_{1}, \mathrm{~K}_{2}, \mathrm{~K}_{3}, \mathrm{~K}_{4}, \mathrm{~K}_{5}$ are calculated according to the following formulas:

$\mathrm{K}_{1}$ - own working capital/capital and reserves; $\mathrm{K}_{2}-$ own working capital/short-term liabilities; $\mathrm{K}_{3}$ - sales revenues/assets; $\mathrm{K}_{4}-$ net profit/earnings; $\mathrm{K}_{5}-$ net profit/capital and reserves; $\mathrm{R}$ - rating presenting the total of weighted financial ratios of company activities. According to this model we calculated R-factors of 30 oil and gas companies considered above for 2010, 2011 and 2012. According to R-factor results only 17 per cent of companies have bankruptcy probability of over $50 \%$, all five ratios of the rest of the companies correspond to their standard level and financial situation of the company is estimated as satisfactory. At the same time 100 per cent of companies must have minimal or low bankruptcy probability according to accounting reports at 2012 year-end (Fig. 3).

Calculations of bankruptcy risk according to Saifullin-Sadykov criterion proved their high reliability under the modern conditions, although they have some limitations as for some companies there is some difference between $\mathrm{R}$ factors, bankruptcy risk probability and real situation in the companies. It can be explained by the fact that this model and its ratios were developed in late 1990s when the economic situation in Russia, strategies of company development and fiscal environment were different. Thus, we come to the conclusion that Altman model is pessimistic and that of Saifullin-Kadykov although allowing estimation of current financial situation of the company does not allow accurate estimate of the probability of crisis situation onset.

\section{Results of Saifullin-Kadykov model} application

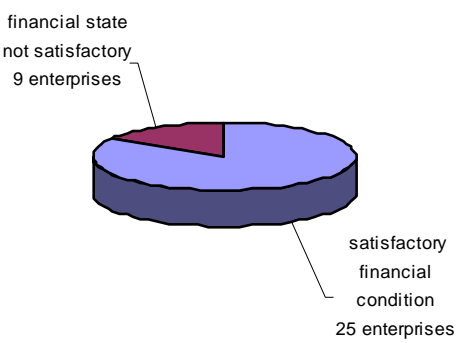

Fig. 3. Results of Saifullin-Kadykov model application

That is why we have developed our own model. On the base of factor analysis we chose 6 indicators and built the model of multiregression which looks as follows

$$
\begin{aligned}
& y=0,672 \cdot x 1+0,378 \cdot x 2-0,07 \cdot x 3- \\
& -0,2 \cdot x 4+0,045 \cdot x 5+0,066 \cdot x 6
\end{aligned}
$$

where $\mathrm{y}-$ resultant indicator (return on total assets); $\mathrm{x}_{1}$ - basic earning power ratio; $\mathrm{x}_{2}$ - return on equity; $\mathrm{x}_{3}-$ return on sales; $\mathrm{x}_{4}$ - ratio of advanced capital turnover intensity; $\mathrm{x}_{5}-$ asset turnover ratio; $\mathrm{x}_{6}-$ working capital to current assets ratio.

In paper [29] by Nedosekin O.A. the author mentions the necessity of integrated approach to solving the problem of company bankruptcy risk management and suggests a model-construction set for bankruptcy risk estimation which can be arranged by expert analyzer according to specific features of the analyzed company.

In paper [30] the authors consider the problem of selecting factors which effect the main source of financial receipts of the company - sales revenues. Selection of factors was completed with application of principal components method. On the base of selected factors the authors develop regression equation showing revenue dependence upon the given factors. In this paper on the base of accounting reports of 33 machine-building companies the authors choose 37 factors. With application of principle components method the authors select 11 factors having significant impact upon company revenue. Regression equation of revenue $P$ looks as follows 
$P=1,83 \cdot 10^{5}+0,02 \times k 1+4,93 \cdot 10^{5} \times k 2+$

$+0,06 \times k 3--3,11 \cdot 10^{4} \times k 4+0,62 \times k 5-$

$-9,83 \cdot 10^{3} \times k 6+8,22 \cdot 10^{5} \times k 7+$

$+2,16 \cdot 10^{6} \times k 8+7,12 \cdot 10^{4} \times k 9-$

$-6,27 \cdot 10^{5} \times k 10-1,15 \cdot 10^{6} \times k 11$.

Here $\mathrm{k}_{1}$ is the total of business assets at company's disposal; $\mathrm{k}_{2}$ - ratio of capital goods in the assets; $\mathrm{k}_{3}-$ amount of net working capital; $\mathrm{k}_{4}$ - working capital ratio; $\mathrm{k}_{5}-$ net profit; $\mathrm{k}_{6}$ - turnover of owned capital; $\mathrm{k}_{7}$ - profitability of operating activities; $\mathrm{k}_{8}$ - return on assets; $\mathrm{k}_{9}$ - return on equity; $\mathrm{k}_{10}$ - working capital wear coefficient; $\mathrm{k}_{11}$ - retirement ratio.

In paper [31] the authors develop a short-term forecast model of bankruptcy risk estimation on the example of OJSC "FSK EES" [33] basing on fuzzy set of bankruptcy risk estimation by Nedosekin [29]. In paper [31] the following results were obtained: procedure of estimation of cell boundaries of values of factors characterizing bankruptcy risk was implemented. Within the given procedure the authors describe the process of collecting and processing expert information; develop membership function determining the degree of estimating belief of the ratio of factor values to one of five factor levels ("very low", "low", "middle", "high", "very high"); the financial situation of OJSC "FSK EES" between 01.01.2008 and 31.12.2010 was estimated; the regressive model of integrated value of company bankruptcy risk and its corridor of errors were developed; on the base of obtained data the authors predict the integrated value of company bankruptcy risk for 2011 .

A similar approach was implemented in [33] for example of some companies in the engineering industry. The necessity of applying the apparatus of fuzzy set theory to the problem of estimating the bankruptcy risk arises from the difficulty of solution experts two main tasks:

1) classification of quality indicators and nonnormalized indicators, the values of which depend on the industry and on the specific activities of the enterprise;

2) linguistic evaluation of certain levels of parameters.

Assessment of the risk of bankruptcy using fuzzy sets includes the following main stages [29].

Stage 1 (Set). Enter the basic sets and subsets of conditions that are described in natural language.

a complete set of States E enterprises is divided into three subsets:

E1 is the subset of States to "trouble";

E2 is a subset of "average quality";

E3 is a subset of "well-being".
Corresponding to the set $\mathrm{E}$ of the complete set of degrees of risk of bankruptcy of $\mathrm{G}$ is divided into three subsets:

G1 is a subset of "the risk of bankruptcy is high";

G2 is a subset of "the risk of bankruptcy of medium";

G3 is a subset of "low risk of bankruptcy".

For an arbitrary individual indicator $\mathrm{Xi}$ the full set of $\mathrm{Bi}$ values is divided into three subsets:

Bi1 - subset "low level of indicator XI";

$\mathrm{Bi} 2$ - subset "average level of the indicator XI";

Bi3 - subset "high level of indicator XI".

Stage 2 (Indicators). Will build a separate set of metrics $X=\{X i\}$ with the total number $N$, which, in the opinion of an expert analyst, on the one hand, affect the assessment of the risk of bankruptcy, and, on the other hand, evaluate different production and financial activity of the enterprise.

Stage 3 (The Importance). Compare each indicator $\mathrm{Xi}$ is the level of significance for the analysis of ri. If all indicators have equal importance (equal or your preferred system of no preferences), then

$$
r_{i}=1 / \mathrm{N} \text {. }
$$

Otherwise, the weighting factor (importance) set by the expert. In this case the rule must be $r_{1}+r_{2}+\ldots+r_{N}=$ $=1$.

Step 4 (Classification degree of the risk). Construct a classification of the current value of the $g$ indicator of the degree $\mathrm{G}$ of risk as a criterion of partitioning of this set into subsets (see tab. 1):

Table 1. Classification of degree of the risk

\begin{tabular}{|l|c|l|}
\hline $\begin{array}{l}\text { The range of } \\
\text { values } \\
\mathrm{g}\end{array}$ & $\begin{array}{l}\text { The } \\
\text { classification } \\
\text { level setting }\end{array}$ & $\begin{array}{l}\text { The degree of } \\
\text { evaluation } \\
\text { confidence }\end{array}$ \\
\hline $0<=\mathrm{g}<=0.2$ & Low & 1 \\
\hline $0.2<\mathrm{g}<0.4$ & Low & $\mu_{1}=5^{*}(0.4-\mathrm{g})$ \\
\cline { 2 - 3 } & Acceptable & $1-\mu_{1}=\mu 2$ \\
\hline $0.4<=\mathrm{g}<=0.6$ & Acceptable & 1 \\
\hline $0.6<\mathrm{g}<0.8$ & Acceptable & $\mu_{2}=5^{*}(0.8-\mathrm{g})$ \\
\cline { 2 - 3 } & High & $1-\mu_{2}=\mu_{3}$ \\
\hline $0.8<=\mathrm{g}<=1.0$ & High & 1 \\
\hline
\end{tabular}

Stage 5 (Classification of indicators values). Construct a classification of the current values $\mathrm{x}$ of the metrics $\mathrm{X}$ as a criterion of partitioning of the full set of possible values into subsets of the form $\mathrm{V}$. 
A number of indicators of financial and economic activity of the enterprise has normative values, on which their classification and assignment to a particular level. But there are some indicators for which there are no generally accepted standards of values (nonnormable indicators). For such indicators it is necessary to build membership functions based on expert or statistical data.

In this work, we used trapezoidal membership functions because they are best suited in the case when there are no clear rules, only their approximate boundaries. This process includes the following main stages.

1) For each indicator on the basis of statistical data for $\mathrm{n}$ periods, need to calculate its average value and standard deviation according to the formulas:

a) the average value

$$
\bar{x}=\frac{\sum_{i=1}^{n} x_{i}}{n}
$$

where $x_{i}$ - the value of the indicator over i period, $\mathrm{n}-$ number of periods;

b) the standard deviation

$$
\sigma=\sqrt{\frac{\sum_{i=1}^{n}\left(x_{i}-\bar{x}\right)^{2}}{n-1}}
$$

Will build a set of three node points of the three level classifier rule:

$$
\begin{aligned}
& \mu_{1}=\bar{x}-\mathrm{t} \cdot \sigma, \\
& \mu_{2}=\bar{x} \\
& \mu_{3}=\bar{x}-\mathrm{t} \cdot \sigma
\end{aligned}
$$

where $t$ is the Student coefficient.

2) For each node classifier fitting that the level of factor is recognized, unequivocally, with absolute certainty $(100 \%)$ of the expert. For example, the point $\mu 1$ responds to the low level of factor $(\mathrm{L}), \mu 2-$ medium condition (M), $\mu 3$ - high $(\mathrm{H})$.

3) Forming the intervals by areas of absolute certainty for low (L), medium (M) and high (H) values according to the formulas:

$$
\begin{aligned}
& \text { L: }\left[-\infty ; \mu_{1}+\left(\mu_{2}-\mu_{1}\right) / 3\right] ; \\
& \text { M: }\left[\mu_{2}-\left(\mu_{2}-\mu_{1}\right) / 3 ; \mu_{2}+\left(\mu_{3}-\mu_{2}\right) / 3\right] \\
& \text { H: }\left[\mu_{3}-\left(\mu_{3}-\mu_{2}\right) / 3 ;+\infty\right] .
\end{aligned}
$$

Intervals $[\mu 1+(\mu 2-\mu 1) / 3 ; \mu 2-(\mu 2-\mu 1) / 3]$ и $[\mu 2$ $+((\mu 3-\mu 2) / 3) ; \mu 3-(\mu 3-\mu 2) / 3]$ are areas of uncertainty.

Table2. Classification of indicator values

\begin{tabular}{|l|c|c|}
\hline The range of values $\mathrm{x}_{\mathrm{i}}$ & $\begin{array}{l}\text { Level } \\
\text { classification } \\
\text { indicator }\end{array}$ & $\begin{array}{c}\text { The degree of } \\
\text { evaluation } \\
\text { confidence }\end{array}$ \\
\hline $\begin{array}{l}-\infty<=\mathrm{x}_{\mathrm{i}}<=\mu_{1}+\left(\mu_{2}-\right. \\
\left.-\mu_{1}\right) / 3\end{array}$ & Low & 1 \\
\hline $\begin{array}{l}\mu_{1}+\left(\mu_{2}-\mu_{1}\right) / 3<\mathrm{x}_{\mathrm{i}}<\mu_{2}- \\
-\left(\mu_{2}-\mu_{1}\right) / 3\end{array}$ & Low & $\begin{array}{l}\beta_{1}=\rho *\left(\mu_{2}-\right. \\
\left.\left(\mu_{2}-\mu_{1}\right) / 3-\mathrm{x}_{\mathrm{i}}\right)\end{array}$ \\
\cline { 2 - 3 } & medium & $1-\beta_{1}=\beta_{2}$ \\
\hline $\begin{array}{l}\mu_{2}-\left(\mu_{2}-\mu_{1}\right) / 3<=\mathrm{x}_{\mathrm{i}} \\
<=\mu_{2}+\left(\mu_{3}-\mu_{2}\right) / 3\end{array}$ & medium & 1 \\
\hline $\begin{array}{l}\mu_{2}+\left(\left(\mu_{3}-\mu_{2}\right) / 3\right)<\mathrm{x}_{\mathrm{i}}< \\
\mu_{3}-\left(\mu_{3}-\mu_{2}\right) / 3\end{array}$ & medium & $\begin{array}{l}\beta_{2}=\rho *\left(\mu_{3}-\right. \\
\left.\left(\mu_{3}-\mu_{2}\right) / 3-\mathrm{x}_{\mathrm{i}}\right)\end{array}$ \\
\cline { 2 - 3 } & High & $1-\beta_{2}=\beta_{3}$ \\
\hline $\begin{array}{l}{\left[\mu_{3}-\left(\mu_{3}-\mu_{2}\right) / 3<=\right.} \\
\mathrm{x}_{\mathrm{i}}<=+\infty\end{array}$ & High & \\
\hline
\end{tabular}

For them, the estimated degree of confidence is calculated according to the formulas:

$$
\begin{aligned}
& \beta_{i}=\rho^{*}\left(b-x_{i}\right), \\
& \rho=0,5 /(b-c), \\
& c=(a+b) / 2,
\end{aligned}
$$

where $a$ is the beginning of the interval, $b$ - the end of the interval, with the middle of the interval, $x_{i}-$ the current value of the indicator. The values obtained are presented in the table 2 .

Stage 6 (evaluation of the level indicator). Let's make an assessment of the current level of performance and bring the results in table (table. 3 ).

Table 3. Summary table of indicators

\begin{tabular}{|c|c|}
\hline Indicator name & The current value \\
\hline $\mathrm{X}_{1}$ & $\mathrm{x}_{1}$ \\
\hline$\ldots$ & $\ldots$ \\
\hline $\mathrm{X}_{\mathrm{N}}$ & $\mathrm{x}_{\mathrm{N}}$ \\
\hline
\end{tabular}

Stage 7 (Classification level indicators). Will hold the classification of the current values of $\mathrm{x}$ on the criterion of table 5 . The result of the classification is the following table (table 4). 
Table 4. Classification of values of $\mathrm{X}$

\begin{tabular}{|c|l|c|c|}
\hline $\begin{array}{l}\text { Indicator } \\
\text { name }\end{array}$ & $\begin{array}{l}\text { The result of classification by } \\
\text { subsets }\end{array}$ \\
\cline { 2 - 4 } & $\mathrm{Bi} 1$ & $\mathrm{Bi} 2$ & $\mathrm{Bi} 3$ \\
\hline $\mathrm{X} 1$ & $\lambda_{11}$ & $\lambda_{12}$ & $\lambda_{13}$ \\
\hline$\ldots$ & $\ldots$ & $\ldots$ & $\ldots$ \\
\hline $\mathrm{XN}$ & $\lambda_{\mathrm{N} 1}$ & $\lambda_{\mathrm{N} 2}$ & $\lambda_{\mathrm{N} 3}$ \\
\hline
\end{tabular}

Step 8 (risk Assessment). Now let's implement the formal arithmetic operations for assessing the risk of bankruptcy g:

$$
\mathrm{g}=\sum_{\mathrm{j}=1}^{3} \mathrm{~g}_{\mathrm{j}} \sum_{i=1}^{N} \mathrm{r}_{i} \lambda_{\mathrm{ij}}
$$

where $g_{j}=0.9-0.4 \cdot(j-1), \lambda_{i j}$ is determined using the table from step 6 .

Step 9 (Linguistic recognition). Classify the obtained value of the degree of risk on the basis of the table data of stage 4 . Thus our conclusion about the degree of risk the company acquires a linguistic form [29].

Using the described approach were assessed for the risk of bankruptcy of OJSC "Ishimbay machinebuilding plant". Membership functions were constructed on the basis of financial statements for the period from the first quarter of 2007 to the first quarter of 2012. All information is obtained from quarterly reports of the Issuer on the official website of the organization [34].

Assessment of the risk of bankruptcy was made on the basis of data for the 4th quarter of 2011 and the first quarter of 2012 the Results were as follows. In Q4 2011 the level of risk of bankruptcy of $56 \%$ is acceptable, and 44\% - high; in the 1st quarter of 2012 the level of bankruptcy risk at $31 \%$ is acceptable and $69 \%$ higher. In respect of this plant was filed to declare the debtor bankrupt in the 1st quarter of 2012

Table 5 shows the results of the assessment of the risk of bankruptcy for four companies, two of which were declared bankrupt. For analysis were calculated 10 indicators of financial and economic activity of the enterprise for 2010 - 2011 and the first quarter of 2012, selected using the method of principal components.

The results of the assessment of the bankruptcy risk to confirm the actual situation of the analyzed enterprises in the 1st quarter of 2012, namely: OJSC "Izhmashstanko" the Decision of Arbitration court of the Udmurt Republic dated 20.02.2012 years declared bankrupt; JSC "Izhevsk machine-building factory" the Decision of Arbitration court of the Udmurt Republic dated 06.04.2012 declared bankrupt; JSC "Machine building plant" Electrostal JSC and "Sibkabel" Tomsk current existing businesses.
Table 5. The results of the assessment of the risk of bankruptcy of enterprises on the basis of values of indicators for the 1st quarter of 2012.

\begin{tabular}{|c|c|c|c|c|}
\hline & $\begin{array}{c}\text { JSC } \\
\text { "Izhmash } \\
\text { stanko", } \\
\text { Izhevsk }\end{array}$ & $\begin{array}{c}\text { JSC } \\
\text { "Izhevsk } \\
\text { machine- } \\
\text { building } \\
\text { plant",Iz } \\
\text { hevsk }\end{array}$ & $\begin{array}{c}\text { JSC } \\
\text { "Machin } \\
\text { e } \\
\text { building } \\
\text { plant", } \\
\text { Elektrost } \\
\text { al }\end{array}$ & $\begin{array}{c}\text { CJSC } \\
\text { "Sibkabe } \\
\text { 1", } \\
\text { Tomsk }\end{array}$ \\
\hline $\begin{array}{c}\text { The level } \\
\text { of risk }\end{array}$ & High & $\begin{array}{c}\text { Acceptab } \\
\text { le } 17,5 \% \\
\text { High } \\
82,5 \%\end{array}$ & $\begin{array}{c}\text { Low } \\
29,5 \% \\
\text { Acceptab } \\
\text { le } \\
70,5 \%\end{array}$ & $\begin{array}{c}\text { Low of } \\
81.5 \% \\
\text { Acceptab } \\
\text { le } \\
18,5 \%\end{array}$ \\
\hline
\end{tabular}

\section{CONCLUSION}

In the paper we have considered typical decision support systems when managing bankruptcy of companies. The authors consider known models of estimating financial stability of companies. They show that there are no universal models of company bankruptcy risk assessment. The limits to applicability of the models depend upon the economic conditions under which the models were obtained, in particular, it was shown that foreign models are hardly suitable for Russian conditions. Besides, the models of financial stability may significantly vary for companies of different industries. Development of the model of company financial stability estimation can be considered as direct problem. To manage bankruptcy risk we should solve the opposite problem - how should the financial indicators be changed for the key indicator to take the required values.

\section{REFERENCES}

[1] E.A. Babkin, A.N. Vizgunov, A.A. Kurkin, O.R. Kozyrev, "General principles of developing intelligent decision-making support systems,“ - N. Novgorod: Nizhegorodsky State Technical University named after R.Ye. Alekseyev, 2008.

[2] E.V. Telipenko, T.Y. Chernysheva, A.A. Zakharova, A.I. Dumchev, "Results of research on development of an intellectual information system of bankruptcy risk assessment of the enterprise," IOP Conference Series: Materials Science and Engineering. - 2015 Vol. 93 - №. 1, Article number 012058.

[3] N.I. Yusupova, Ye.O. Volik, "Bankruptcy monitoring with application of intellectual data analysis methods," Bulletin of USATU. - 2008, issue 2, volume 10.

[4] www.rae.ru/snt/?section=content\&op=show_article\&artic le_id=6000.

[5] bourabai.ru/tpoi/dss.htm. 
[6] corpsys.ru/ToOrder/DSS.aspx.

[7] journal-discussion.ru/publication.php?id=43.

[8] www.lerc.ru/?art=8\&page=32\&part=bulletin.

[9] E.V. Telipenko, A.A. Zakharova, S.P. Sopova, "Forecasting risk of bankruptcy for machine-building plants," IOP Conference Series: Materials Science and Engineering. - 2015 - Vol. 91, Article number 012066

[10] E.V. Telipenko, A.A. Zakharova, "Bankruptcy risk management of a machine builder," Applied Mechanics and Materials. - 2014 - Vol. 682. - pp. 617-622.

[11] A.A. Zakharova, E.V. Telipenko, "Information system of bankruptcy risk management of an enterprise," 7th International Forum on Strategic Technology (IFOST - 2012): Proceedings: in 2 vol., Tomsk, September 18-21, 2012. - Tomsk: TPU Press, 2012 Vol. 1 - pp. 539-543.

[12] "Analysis of financial accounts," textbook.. $-2^{\text {nd }}$ edition / Under the general ed. of M.A. Vahrushina. M.: INFRA, 2011. 431 p.

[13] K.V. Baldin, "Mathematical methods and models in economics," textbook / K.V. Baldin, V.N. Bashlykov, A.V. Rukosuev; under the general ed. of K.V. Baldin. M.: FLINTA, 2012. $328 \mathrm{p}$.

[14] "Models of bankruptcy (diagnostics and estimation of bankruptcy risk), " [digital resource] / site Financial manager financem.info. Access mode: http://finance-m.info/bankruptcy_models.html (accessed date 05.05.2015).

[15] "Model of company bankruptcy by Saifullin-Kadykov," [digital resource] / site Financial analysis and investment analysis of a company. Access mode: http://www.beintrend.ru/2011-06-20-1705-06 (accessed date 7.09.2015).

[16] "Springate model of company bankruptcy forecasting," (1978). [digital resource] / site Financial analysis and investment analysis of a company. Access mode: http://beintrend.ru/springate. Source: Springate, Gordon L.V., "Predicting the Possibility of Failure in a Canadian Firm". Unpublished M.B.A. Research Project, Simon Fraser University, January 1978.

[17] "Taffler model (four-factor bankruptcy model)" [Digital resource] / site Financial manager finance-m.info. Access mode: http://finance-m.info/bankruptcy_model_taffler.html (accessed date 05.05.2015).

[18] "Chesser model" [Digital resource] / site www.afdanalyse.ru - Analysis of financial situation of a company. Access mode: http://afdanalyse.ru/publ/finansovyj_analiz/1/model_chessera/16-1-0142 (accessed date 7.09.2015).

[19] T.A. Pozhidayeva, "Analysis of financial accounts: study guide," / T.A. Pozhidayeva. 3d ed., stereotype. M.: KNORUS, 2010. -320 p.

[20] "Springate predictive model of solvability," [Digital resource] / / site www.afdanalyse.ru - Analysis of financial situation of a company. Access mode: http://afdanalyse.ru/publ/finansovyj analiz/1/prognoznaja model pla tezhesposobnosti_springejta/13-1-0-39 (accessed date 7.09.2015).

[21] "Four-factor model of bankruptcy risk assessment by R. Lis," [Digital resource] / site Financial analysis and investment analysis of a company. Access mode: http://www.beintrend.ru/201112-05-17-20-28 (accessed date 7.09.2015).

[22] Fulmer J. G. et al. (1984): A Bankruptcy Classification Model For Small Firms. Journal of Commercial Bank Lending, July 1984, 25-37 pp.

[23] "Investfunds," URL: http://stocks.investfunds.ru/stocks/ (дата обращения: 18.02.2016). s.investfunds.ru

[24] A.A. Mitsel, M.A. Soboleva, "Analysis of financial stability of Russian mobile communication companies," Financial analytics: problems and solutions. - 2015, iss. 6 (240). - P. 24-31.

[25] "MTS, Megafon and Beeline," [Digital resource] / site RosInvest.Com/ Access
http://rosinvest.com/acolumn/blog/high_technology/469.html (accessed date 5.04.2015).

[26] "About a company" [Digital resource] / site of Beeline company. Access mode: http://about.beeline.ru/index.wbp (accessed date 30.04.2015).

[27] "Detailed information on MTS" [Digital resource] / site www.mts.ru. Access mode: http://www.company.mts.ru/comp/presscentre/briefly/ (accessed date 30.04.2015).

[28] A.D. Sheremet, R.S. Saifullin, "Methods of financial analysis of a company," - M.: Delo. 1998. 320 p.

[29] A.O. Nedosekin, "Fuzzy set analysis of fund investments risk," - SPb.: Sezam, 2002. 167 p.

[30] A.A. Mitsel, "Estimation of financial and business operation factors influence upon sales revenues," / A.A. Mitsel, Ye.V. Telipenko, Economic analysis. Theory and practice. 2011. №27(234). pp. 57-64.

[31] A.A. Mitsel, "Models of risk and company bankruptcy prediction,“/ A.A. Mitsel, A.A. Kabalin, Risk management. 2013. №1. pp. 44-52.

[32] "Official site of Federal Grid Company of Unified Energy System,“ [Digital resource]. - Access mode: http://www.fskees.ru/shareholders_and_investors/disclosure_of_information/quarter ly_reports/ - free.

[33] E. V. Telipenko, A. A. Zakharova. Problems of forecasting of risk of bankruptcy of the enterprises of a machinebuilding complex/ VI of the International scientific and practical conference "Innovative technologies and economy in mechanical engineering"/ Yurginsky institute of technology. - Tomsk: Publishing house of Tomsk polytechnical university, 2015. - Page 262-266. Access mode: http://www.lib.tpu.ru/fulltext/c/2015/C30/060.pdf - free.

[34] "Official site of "Ishimbay machine-building plant" [Digital resource]. - Access mode: www.kungur.com. - free. 